\title{
RELATIONSHIP OF RELIGIOUSNESS AND RELIGIOUS COPING WITH QUALITY OF LIFE AMONG WAR TRAUMA SURVIVORS
}

\author{
Senadin Fadilpašić ${ }^{1}$, Daniel Maleč ${ }^{2}$ \& Alma Džubur-Kulenović ${ }^{1}$ \\ ${ }^{l}$ Department of Psychiatry, University Clinical Center Sarajevo, Sarajevo, Bosnia and Herzegovina \\ 2 Faculty of Education Sciences, University of Sarajevo, Sarajevo, Bosnia and Herzegovina
}

received: 2.12.2016;

revised: 4.5.2017;

accepted: 28.5 .2017

\begin{abstract}
SUMMARY
Background: Long-term posttraumatic outcomes such as quality of life are dependent on a series of factors from the very exposure to traumatic events and stress appraisals, personality traits, posttraumatic growth, symptoms of Posttraumatic stress disorder (PTSD) and different coping strategies to religiousness and religious coping styles. Except of exposure to traumatic events and related stress, all other variables may have indirect mediating effects on long-term posttraumatic outcomes. The main aim of this cross-sectional study is to explore relative independent contribution of these variables in the explanation of quality of life among war trauma survivors, with a special emphasis on the variables of religiousness and religious coping.

Subjects and methods: The research was conducted on 353 subjects who experienced war related traumatic events during the war in Bosnia and Herzegovina $(B \& H)$. The data was collected through several self-report measuring instruments: Manchester Short Assessment of Quality of Life, Stressors Check List (SCL); Religiousness Scale, Social Support Resources Scale; Religious Problem-Solving Scale, Brief RCOPE, Posttraumatic Growth Inventory and Mississippi Scale for PTSD.

Results: According to the results of the study, experience of loss and frequent exposure to war trauma and high levels on the primary stress appraisals, self-directing coping style and PTSD-symptoms were associated with lower perceived quality of life among the subjects. High levels of extrinsic religious orientation, effect of religiousness on social behavior, positive religious coping and posttraumatic growth were associated with higher perceived quality of life among subjects. These variables showed significant independent contribution to the prediction of the values on quality of life.

Conclusions: Results of the study have a scientific significance in understanding the importance and mediating role of religiousness and religious coping for quality of life perception as one of long-term posttraumatic outcomes. Effects of religiousness on social behavior and positive religious coping showed particularly significant contribution across all prediction models for the quality of life.
\end{abstract}

Key words: war trauma - PTSD - religiousness - social support - religious coping - quality of life

$$
* * * * *
$$

\section{INTRODUCTION}

A large body of literature has been accumulated on how individual efforts to manage distressing problems shape psychological outcomes of stress. Research has shown, that long-term outcomes of traumatic events such as subjective wellbeing are influenced by individual attributes, such as personal beliefs (religiousness), situational factors such as social support, stress appraisals and different coping strategies. The majority of researchers in this area acknowledge the contextual and dynamic view of the constructs of stress and coping, as postulated by Lazarus' transactional theory (Lazarus \& Folkman 1984). The theory views the processes of appraisals and coping as critical mediators of personenvironment relationship and various long-term outcomes such as Quality of life (QOL). World health organization (WHO) defines QOL as an individual's perception of the position in a specific cultural, social and environmental context (World Health Organization 1998). According to Felce and Perry (1993), QOL represents overall well-being that includes objective factors and subjective evaluations of physical, material, social and emotional wellbeing (e.g. personal development and meaningful activities), which all are perceived through personal evaluative systems of individuals.
Coping is regarded as a shifting process in which a person must, at certain times, rely more on one strategy and at other times on some other forms of coping as the status of person-environment relationship changes (Lazarus 1993, 2000, Lazarus \& Folkman 1987). Pargament (1997) defined religious coping as efforts to understand and deal with life stressors in ways related to the sacred. The term "sacred" refers not only to traditional notions of God, divinity or higher powers, but also to other aspects of life that are associated with the divine. According to Pargament's theory (1997) religious coping serves multiple functions, including the search for meaning, intimacy with others, identity, control, anxietyreduction and transformation. Religious coping involves behaviors, emotions, relationships and cognitions which are dynamic and change over time and circumstances and lead to helpful or harmful outcomes. Because of its focus on the ways religion expresses itself in particular life situations, religious coping may add important information of religion and its links to health and wellbeing, especially among people facing critical problems in life. That dispositional religiousness and religious coping associated with both mental and physical health has been firmly established within the scientific literature (Koenig 2008, Levin et al. 2011), particularly in the context of adversity (Ai \& Park 2007, Linley \& Joseph 
2004). In general, the effects tend to be positive, including lower levels of psychological distress and depressive symptoms, better quality of life, and decreased morbidity and mortality (Masters \& Hooker 2013, Park \& Slattery 2013), well-being (Koenig et al. 2012, Paloutzian \& Park 2013, Pargament et al. 2013); comfort (Exline et al. 2000) and satisfaction with life (Abu-Raiya \& Agbaria 2015). Religious and spiritual resources are generally helpful to people confronting major life stressors (Abu-Raiya \& Pargament 2015). Relative to less religious or nonreligious people, those who are religious tend to be more socially active and have higher levels of perceived social support and optimism (Ai \& Park, 2007; Chan et al. 2012). The relationship between religiousness and subjective wellbeing is mediated by social support and individuals' motivation to make sense of situations. Helgeson (2003) asserts that perceived social support is an important predictor of QOL. He points out that perception of social support has stronger connection with QOL perception than received support from social environment.

A meta-analysis (Ano \& Vasconcelles 2005) found that across various stressful life situations, religious coping methods are consistently associated with improved psychological outcomes, including acceptance, hope, optimism and life satisfaction. It is important to note, however, that not all religious coping strategies are the same, and their influence on post-disaster functioning can vary. Pargament and colleagues (Pargament 1997, Pargament et al. 2011, Witvliet et al. 2004, Berg 2011) draw distinctions between positive and negative religious coping. Negative religious coping strategies have been found to be associated with mental health problems, especially depression (e.g., Harrison et al. 2001, Pargament et al. 1998) and PTSD (Gerber et al. 2011). On the other hand, there is some evidence suggesting that positive religious coping can help explain why religious individuals have better psychological outcomes after a natural disaster (Smith et al. 2000). Pargament et al. (1989) created a dispositional measure of religious coping that assessed how people typically use religion as a way of enhancing the sense of control in coping. This measure consisted of three different religious coping scales - collaborative, self-directing, and deferring religious coping methods. Control was seen as derived through a relationship with God (collaborative), through the freedom God gives people to solve problems themselves (self-directing), and through the delegation of responsibility for problem solving to God (deferring). As theorized, researchers have found that collaborative religious coping is associated with positive outcomes, such as increased self-esteem and lower levels of depression (Pargament et al. 1989, Wong-McDonald \& Gorsuch 2000). As expected, the deferring approach appears to have mixed implications, relating to higher levels of depression and lower levels of competence, but also to higher levels of well-being (Pargament et al. 1989, Wong-McDonald \& Gorsuch 2000). Surprisingly, self-directing coping has also been associated with mixed outcomes. More self-directing religious coping has been related to higher levels of self-esteem and belief in personal control. At the same time it has also been linked to higher levels of depression and lower levels of well-being (Hathaway \& Pargament 1990, Wong-McDonald \& Gorsuch 2000).

Previous research have confirmed the connection between external events, personality and the evaluation of QOL (Diener et al. 1999). In the analysis of this interaction, the nature of external events must be taken into account as different circumstances have different effects on that interaction. For instance, traumatic events are by definition external factors that have negative effects on individuals' lives. When it comes to the QOL among war victims, its correlation with the exposure to war trauma, even long time after traumatic events, has been empirically confirmed (Sundquist et al. 1998, Eisenman et al. 2003). In fact, negative effects of war related trauma may last for many years (Freitag et al. 2012). Lower QOL among veterans and refugee population is consistently linked to war experience and consequent PTSD symptoms (Schnurr et al. 2009, Priebe at al. 2009. Bravo-Mehmedbašić et al. 2010). Rapaport et al. (2005) have reported that even up to $59 \%$ of persons with PTSD perceive very low QOL. There are severe impairments in functioning in different area of life among patients with PTSD. Teodorescu et al. (2012) reported a significant presence of posttraumatic growth aside from high prevalence of PTSD within samples of war refugees. According to the results of their research, pathological symptoms negatively correlated with QOL and positively correlated with post-migration stressors.

The aim of the research was to examine a relative contribution of the dispositional religiousness, perceived social support, religious coping styles and strategies, primary and secondary stress appraisals, PTSD and Posttraumatic growth to the QOL as a long term outcome of war traumatic experiences, among people who experienced trauma during war in Bosnia and Herzegovina (B\&H).

\section{SUBJECTS AND METHODS}

\section{Subjects}

The research was conducted on the targeted population of current residents of Sarajevo Canton, who experienced war related traumatic events during the war in B\&H. Accordingly, the first exclusion criterion was if a participant had not experienced at least one war related traumatic event. The second exclusion criterion was if a person presented mental illness due to the organic brain dysfunction. Information regarding such an illness was obtained either by patients self-reports or evaluations of medical records if available at the interview. The third exclusion criterion was the age of the participant at the time of data collection. According to these criteria, we had excluded $n=14$ participants. The sample consisted 
of $n=353$ subjects aged between 35 and 70 (with mean age 45). This study had cross sectional design. The study was not registered at public registry before the data collection and analysis. Snowball sampling method was utilized. At the beginning of the data collection, "mapping" of the terrain had been done, and establishing contact with "social network" of target groups (neighbors, acquaintances, NGO activists, and mental health professionals) was established. Once contact was established, we chose $n=10$ members of the target category (seeds) that meet the criteria of inclusion, which were the initial source of information. Through these initial participants (seeds) we came to the other participants involved in the sample (provided that they meet the criteria for inclusion). This initial sample was made up of several categories of subjects (war veterans, civil war participants) and heterogeneous on some relevant characteristics (veterans and civil war participants who were of different socio-economic status, age, etc.). The sample size had been planned in accordance with optimal case number to variable number ratio. The minimum ratio is 7 to 10 cases per variable and all above those values is acceptable. Larger ratio values in our sample enable greater power of statistical generalization. All participants signed informed consent prior to inclusion in the study and administration of assessment instruments. The data collection was performed within a period of three months (from March to June, 2014).

\section{Measures}

The questionnaire for the collection of socio-demographic data was constructed for the purposes of this study, and included information on age, gender, employment status, education, participation in the war, religious denomination and legal status.

Manchester Short Assessment of Quality of LifeMANSA (Priebe et al. 1999) was used to measure the QOL as an long term outcome of war trauma. It contains 16 questions measuring subjects' satisfaction with their lives in general (total result on the scale) as well as with different aspects of their lives (results on the subscales related to satisfaction with employment, finances, friendships, hobbies, accommodation, personal safety, household members, family relations, physical and mental health). The questions are seven-point Likert-type scales (from $1=$ couldn't be worse to 7 $=$ couldn't be better). Mean score of all satisfaction ratings is used as the total measure of subjective QOL (MANSA-tot). The MANSA has been validated in Sweden for seriously mentally ill persons (SMI), where the internal consistency was confirmed high (Cronbach's $\alpha=0.81$ ) (Björkman \& Svensson 2005). This instrument was also applied by a number of authors on samples of war victims in Croatia, Bosnia \& Herzegovina and Serbia and average internal consistency determined in these studies was $\alpha=0.74$ (Priebe et al. 2009). In our research, $\alpha$-Cronbach was calculated and its value was $\alpha=0.912$. Exploratory factor analysis was conducted. Principal component analysis method with oblimin rotation was employed. The results of the analysis have shown one-factor-structure. The extracted factor explained $50.1 \%$ of the total variance.

Stressors Check List (SCL) is a part of PSS-3 (Powell et al. 1998), an instrument developed in order to measure frequency of traumatic events and related subjective experience of stress intensity, PTSDsymptoms and their influence on everyday life. SCL consists of 27 items registering type and frequency of different traumatic events and the extent to which examinees assess these traumatic events as stressful. For each of these 27 questions, examinees had to answer if these events had or had not been war related. The intensity of stress related to a traumatic event was assessed on a five-point Likert-type scale ( 0 -was not stressful at all, 1=a little stressful, 2=moderately stressful, $3=$ pretty stressful and $4=$ very stressful). In this research, SCL was applied in order to measure two predictor variables: frequency of stressful events and primary stress appraisal. Variables threat and loss as components of secondary stress appraisal were also measured as addition of this instrument.

Religiousness Scale (Ljubotina 2004) was developed to measure three distinct dimensions of religiousness: religious beliefs (intrinsic religious orientation), ritual religiousness (extrinsic religious orientation) and the effect of religiousness on social behavior. Scale is consisted of 27 questions that are four-point Likert-type scales $(0=$ not true at all; $1=$ mostly not true; $2=$ partly true; $3=$ mostly true). The score on a scale is defined as the mean of ratings on the items from that scale. According to Ljubotina (2004), reliability of the scales (Cronbach's $\alpha$ ) varies from 0.76 to 0.95 . The values of reliability calculated in our research were $\alpha=0.955$ for religious beliefs scale and $\alpha=0.78$ for effect of religiousness on social behavior scale. Exploratory factor analysis was performed. Principal component analysis method with oblimin rotation was used. Three different factors were extracted, each of which had eigen value greater than 1 . These three factors explained $65.392 \%$ of total variance.

Religious Problem-Solving Scale (Pargament et al. 1989 ) is defined by 18 items. Each of the items is a fivepoint Likert-type scale (from $1=$ strongly disagree to $5=$ strongly agree). The scale contains three subscales and covers three related variables: collaborative coping style, self-directing coping style and deferring coping style. The results on the subscales are defined as mean ratings on corresponding items. According to the authors of the scale, each subscale has high internal consistency $(\alpha=0.89$ for collaborative coping style, $\alpha=0.89$ for self-directing coping style and $\alpha=0.86$ for deferring coping style). In the research presented in this paper, Cronbach's reliability coefficients were also calculated and their values proved to be medium ( $\alpha=0.780$ for self-directing coping style) to high 
( $\alpha=0.919$ for collaborative coping style and $\alpha=0.914$ for deferring coping style). Exploratory factor analysis was performed. Principal component analysis method with oblimin rotation was used. Three different factors were extracted, each of which had eigen value greater than 1 . These three factors explained $70.275 \%$ of total variance.

A part of Social Support Resources Scale -SSR (Vaux 1988) was applied in order to measure perceived social support. Scale contains 5 Likert-type rated items and response options ranged from 1 to $5(1=$ not satisfied at all to $5=$ totally satisfied). Results on the scale is a mean value of item ratings. Vaux (1988) reported it's medium reliability $\alpha=0.75$. In our research a high value of reliability was confirmed $(\alpha=0.878)$. Exploratory factor analysis was conducted. Principal component analysis method with oblimin rotation was employed. The results of the analysis showed onefactor-structure. The extracted factor explained $67.4 \%$ of the total variance.

Brief Religious Coping Scale (Pargament et al. 1998) was applied to measure religious coping. The instrument contains two subscales related to two predictor variables: positive religious coping and negative religious coping. Both subscales have seven items that are 4-point Likert-type scales. The scales are rated from $0=$ not at all to $3=$ a great deal. Results on the scales are defined as mean value of ratings on the items. A higher score on the positive subscale indicates a higher level of positive coping, whereas a higher score on the negative subscale indicates a higher level of negative religious coping. Pargament (1990) reported satisfactory internal consistencies for the both scales, ranging from medium $(\alpha=0.81)$ to high $(\alpha=0.92)$. In our research, high reliability was found for positive religious coping $(\alpha=0.92)$ and medium reliability for negative religious coping $(\alpha=0.76)$. Exploratory factor analysis was performed. Principal component analysis method with oblimin rotation was used. Two distinctive factors were extracted, each of which had eigen value greater than 1 . These two factors explained $50.73 \%$ of total variance.

Posttraumatic Growth Inventory PTGI (Tedeschi \& Calhoun 1995) was used to measure posttraumatic growth. The scale contains 21 items divided into five subscales. The items are five-point scales ranging from 1 (no change at all) to 5 (very big change). Aside from subscale scores, there is a total score of posttraumatic growth. The scores are defined as mean values of corresponding items. In this research, only the total measure of posttraumatic growth was used as a predictor variable. According to the authors of the PTGI, the total scale has high internal consistency $(\alpha=0.90)$. In the research presented in this paper, a high value of internal consistency for the total scale was also confirmed $(\alpha=0.956)$. Exploratory factor analysis was conducted. Principal component analysis method was employed with oblimin rotation. The results of the analysis showed one-factor-structure. The extracted factor explained $57.09 \%$ of the total variance.

Mississippi Scale for PTSD (Keane 1988) is a questionnaire used to measure the presence and severity of PTSD symptoms. It contains 35 questions that are Likert-type scales rated from 1 to $5(1=$ not true at all to $5=$ absolutely true). The score on the scale is a sum of the values from all items. According to the previous research in $\mathrm{B} \& \mathrm{H}$, average value of internal consistency of the scale is $\alpha=0.94$, while in our research similar internal consistency was obtained. Exploratory factor analysis was conducted. Principal component analysis method with oblimin rotation was employed. The results of the analysis showed one-factor-structure. The extracted factor explained $54.6 \%$ of the total variance.

\section{Statistical Analysis}

Several statistical analyses were performed using the computer software SPSS-21 for Windows. Frequencies and percentages were calculated for the description of binary coded variables. Mean, range and standard deviation were calculated for all variables with scale values. Also, point-biserial, Pearson's and multiple correlation coefficients were calculated. Hierarchical multiple regression analysis was employed in order to identify significant predictors of the values of the criterion variable QOL. In the procedure, multiple correlation and multiple determination coefficients were calculated, along with F-ratios for determining the significance of prediction models, increase of the proportion of criterion variance explained at each step and regression coefficients (at each block and step). Predictor variables of secondary stress appraisal (loss and threat) were binary coded with values $0=$ not indicating presence of loss or threat appraisals and $1=$ indicating presence of loss or threat appraisals so they could enter the regression analysis.

\section{RESULTS}

The ratio of male to female participants is $42 \%$ males and $58 \%$ females. All the subjects were in $\mathrm{B} \& \mathrm{H}$ during the war and $22 \%$ of them were actively involved in combats, while the $78 \%$ of them were civilians at the time. Within this sample, $84.5 \%$ of the participants are official members of Muslim Religious Communion, $5.6 \%$ are members of Catholic and $3.6 \%$ are members of Orthodox religious denomination. There were also $1.8 \%$ of the participants belonging to Jewish Religious Communion. Most of the participants were employed at the time of examination $(70.8 \%)$, but there were $17.5 \%$ who were unemployed and $11.7 \%$ who were retired at the time. Majority of the participants were domicile people $(84.4 \%)$ and the rest of them were exiles and returnees $(15.8 \%)$. Most of them had university degree education $(56.8 \%)$ and the rest of them had medium or low expertise education (43.2\%). 
Table 1. Means and standard deviations of the results on the criterion and predictor variables

\begin{tabular}{lcc}
\hline Variable & Mean (range) & Std. Deviation \\
\hline Quality of life & $5.14(1.91-7)$ & 0.860 \\
Frequency of stressful events & $7.40(1-20)$ & 3.737 \\
Primary stress appraisal & $1.11(0.09-3.64)$ & 0.650 \\
Intrinsic religious orientation & $2.35(0-3)$ & 0.771 \\
Extrinsic religious orientation & $1.89(0-3)$ & 0.675 \\
Influence of religiousness on social behavior & $1.82(0-3)$ & 0.672 \\
Collaborative coping style & $3.26(1-5)$ & 1.029 \\
Self-directing coping style & $2.39(1-5)$ & 1.137 \\
Deferring coping style & $2.70(1-5)$ & 0.891 \\
Perceived social support & $3.05(1-5)$ & 0.962 \\
Positive religious coping & $2.62(1-4)$ & 0.658 \\
Negative religious coping & $1.76(1-4)$ & 0.471 \\
Posttraumatic growth & $2.43(0-4.86)$ & 1.123 \\
PTSD symptoms & $100.18(54-119)$ & 7.760 \\
\hline
\end{tabular}

Correlation and multiple regression analysis were performed for criterion variable QOL. All assumptions needed for parametric statistical analysis were met. The analysis of the data distribution showed that predictor variables and the criterion variable had acceptable skeweness and kurtosis indices within -1 to 1 range and non-significant Kolmogorov-Smirnov Z-values, indicating normal multivariate distributions. Mean values, range (minimum and maximum values) and standard deviations of predictors and the criterion variable are shown in the table 1. Correlation coefficients between the QOL and predictors are significant in most of the cases (Table 2). Only the variables of loss appraisal and deferring coping style did not correlate significantly with QOL. According to the values of correlations, QOL correlates positively with religiousness (intrinsic religious orientation, extrinsic religious orientation and effect of religiousness on social behavior), collaborative coping style, perceived social support, positive religious coping and posttraumatic growth. Higher values of these predictors are followed by higher levels of QOL and vice versa. Opposite to that, QOL correlates negatively with the rest of the predictors (frequency of traumatic events, primary stress appraisal, self-directing coping style, negative religious coping and symptoms of PTSD). Higher values of these predictors are followed by lower values of QOL and vice versa. A notable amount of correlations among predictors are also significant but the values and direction of these correlations follow a sensible pattern. This means that the largest positive values of the coefficients are within the sets of predictors and all the values (both positive and negative) are expected in accordance to theoretical frames and previous research. As high correlations among predictors could indicate a possible problem regarding collinearity, it required utilization of collinearity diagnostics. Values of variance inflation factor (VIF) smaller than 5, values of tolerance greater than 0.20 and values of condition index (CI) smaller than 30 were found, therefore no problems of collinearity among predictor vari- ables were obtained. Sets of the predictor variables were entered into the equation in steps. At this process, the order of entering the predictor was based on previously described theoretical model and other authors' research findings. Further, the analysis of outliers was performed. Accordingly, all the cases $(n=6)$ that had not fitted within $95 \%$ elipse interval of bivariate distribution as well as those one with substantially large Mahalanobis distance value were removed.

The order in which the sets (groups) of predictors were entered into regression analysis was as follows: (1) traumatic events (frequency of traumatic events and primary stress appraisal), (2) religiousness (intrinsic and extrinsic religious orientation and effect of religiousness on social behavior), (3) secondary stress appraisals (loss and threat), (4) coping styles (collaborative coping style, self-directing coping style, and deferring coping style), (5) perceived social support, (6) religious coping (positive and negative religious coping) and (7) posttraumatic adjustment (posttraumatic growth and symptoms of PTSD). At the first step of the analysis, the frequency of traumatic events and primary stress appraisal entered the equation, thus creating the first model of prediction. The model with this set of predictors was significant $(\mathrm{F}=18.114, \mathrm{df}=2$ and $\mathrm{p}<0.001)$ and explained $9.2 \%$ of the variance of the QOL. Although regression coefficients of these predictors were not statistically significant, the model itself is. The regression coefficients are negative, meaning that the more frequent was the exposure of the subjects to traumatic events and more stressful these events were perceived by the subjects, QOL was rated lower. Regression coefficients of the predictors were not significant even in the last model of prediction (see $\beta^{\mathrm{a}}$ values in the last column of the table 3 ). At the second step, intrinsic religious orientation, extrinsic religious orientation and effect of religiousness on social behavior entered the equation. These predictors, taken together, were statistically significant $(\mathrm{F}=16.249$, $\mathrm{df}=5$ and $\mathrm{p}<0.001)$ and explained another $9.5 \%$ of variance of the QOL. The regression coefficients of 


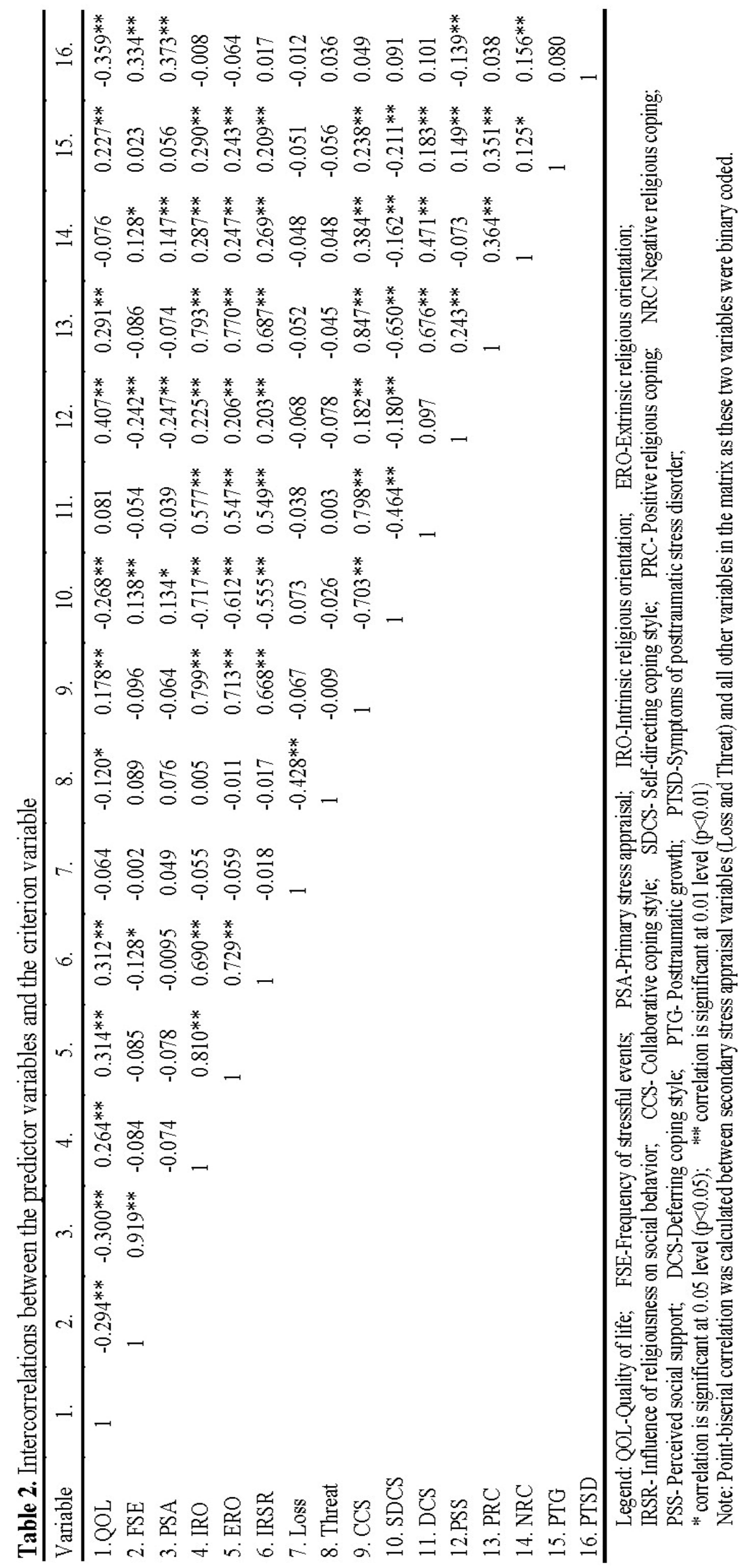


Table 3. Multiple hierarchical regression analysis for the criterion variable Quality of life

\begin{tabular}{|c|c|c|c|c|c|c|c|c|}
\hline \multirow{2}{*}{ Group of predictor variables } & \multirow{2}{*}{$\mathrm{R}$} & \multirow{2}{*}{$\mathrm{R}^{2}$} & \multirow{2}{*}{$\Delta \mathrm{R}^{2}$} & \multirow{2}{*}{$\beta$} & \multirow[t]{2}{*}{$\mathrm{r}$} & \multirow{2}{*}{$\beta^{\mathrm{a}}$} & \multicolumn{2}{|c|}{$95 \%$ interval of $\mathrm{B}^{\mathrm{a}}$} \\
\hline & & & & & & & Lower bound & Upper bound \\
\hline Traumatic events & 0.30 & 0.09 & $0.09 * * *$ & & & & & \\
\hline Frequency of stressful events & & & & -0.12 & $-0.29 * *$ & -0.08 & -0.07 & 0.03 \\
\hline Primary stress appraisal & & & & -019 & $-0.30 * *$ & -0.03 & -0.71 & 0.56 \\
\hline Religious orientation & 0.43 & 0.19 & $0.10 * * *$ & & & & & \\
\hline Intrinsic religious orientation & & & & -0.03 & $0.26^{* *}$ & -0.05 & -1.15 & 0.67 \\
\hline Extrinsic religious orientation & & & & $0.20^{*}$ & $0.31 * *$ & 0.09 & -0.09 & 0.32 \\
\hline $\begin{array}{l}\text { Influence of religiousness } \\
\text { on social behavior }\end{array}$ & & & & $0.16^{*}$ & $0.31 * *$ & $0.20 * *$ & 0.09 & 0.43 \\
\hline Secondary stress appraisals & 0.45 & 0.20 & $0.02 *$ & & & & & \\
\hline Loss & & & & -0.10 & -0.06 & -0.08 & -0.38 & 0.03 \\
\hline Threat & & & & $-0.14 * *$ & $-0.12^{*}$ & $-0.10 *$ & -0.33 & -0.01 \\
\hline Coping styles & 0.48 & 0.23 & $0.03 * *$ & & & & & \\
\hline Collaborative coping style & & & & -0.19 & $0.18^{* *}$ & $-0.24 *$ & -0.39 & -0.01 \\
\hline Self-directing coping style & & & & -0.14 & $-0.27^{* *}$ & -0.08 & -0.16 & 0.03 \\
\hline Deferring coping style & & & & -0.08 & 0.08 & -0.04 & -0.18 & 0.11 \\
\hline Perceived social support & 0.55 & 0.31 & $0.07 * * *$ & $0.29 * *$ & $0.41 * *$ & $0.24 * *$ & 0.14 & 0.30 \\
\hline Religious coping & 0.57 & 0.32 & $0.01 *$ & & & & & \\
\hline Positive religious coping & & & & $0.23^{*}$ & $0.29 * *$ & $0.20^{*}$ & 0.02 & 0.51 \\
\hline Negative religious coping & & & & -0.07 & $-0.08 * *$ & -0.06 & -0.29 & 0.07 \\
\hline Posttraumatic adjustment & 0.63 & 0.39 & $0.07 * * *$ & & & & & \\
\hline Posttraumatic growth & & & & $0.14 * *$ & $0.23 * *$ & $0.14 * *$ & 0.04 & 0.18 \\
\hline PTSD-symptoms & & & & $-0.27 * * *$ & $-0.36^{* *}$ & $-0.27 * * *$ & 0.00 & 0.00 \\
\hline Summary equation Total $\mathrm{cR}^{2}=0.366$ & $\mathrm{~F}=1$ & $69^{* * *}$ & & & & & & \\
\hline
\end{tabular}

$*$ significant at $\mathrm{p}<0.05$ level, $* * \mathrm{p}<0.01, * * * \mathrm{p}<0.001$

$\mathrm{R}=$ multiple correlation coefficient; $\quad \mathrm{R}^{2}=$ multiple determination coefficient; $\quad \Delta \mathrm{R}^{2}=$ increase in the amount of criterion variance explained after entering a new set of predictors into regression analysis; $r=$ coefficient of bivariate correlation between a predictor and the criterion variable; $\beta=$ standardized regression coefficient for a predictor variable entered into equation at a particular step of the analysis; $\mathrm{B}^{\mathrm{a}}=$ unstandardized regression coefficient for a predictor variable entered into equation at the last step of the analysis; $\quad \beta^{\mathrm{a}}=$ standardized regression coefficient for a predictor variable entered into equation at the last step of the analysis; Total $\mathrm{cR}^{2}=$ corrected multiple determination coefficient for the regression equation including all the predictor variables

extrinsic religious orientation and effect of religiousness on social behavior were statistically significant $(p<0.05$ for both predictors). The first two predictors had positive regression coefficients. Thus, increase in the values of extrinsic religious orientation and in the values of effect of religiousness on social behavior was followed by higher subjects' ratings of QOL. In the last model of prediction effect of religiousness on social behavior maintained significant contribution to the prediction power of the model. At the third step, secondary appraisals (threat and loss) entered the equation. This model was statistically significant $(\mathrm{F}=12.851, \mathrm{df}=7$ and $\mathrm{p}<0.001)$. Secondary appraisals explained another $1.7 \%$ of variance of QOL. The regression coefficients of threat and loss were both negative. The coefficient of the threat appraisal was significant $(p<0.05)$. Higher values of loss appraisal were associated with lower ratings on the QOL. This predictor also had a significant regression coefficient at the last step of the regression analysis. At the fourth step, religious coping styles entered the equation. The model of prediction was significant at $1 \%$ level $(\mathrm{F}=10.579, \mathrm{df}=10$ and $\mathrm{p}<0.001)$. This set of predictors explained $2.9 \%$ of the QOL variance $(p<0.001)$. All the predictors in the model had insignificant negative values of regression coefficients. Although none of these predictors were significant individually, together they contribute to the predictive power of the model. Collaborative coping style had significant contribution to the predictive power of the model at the last step $(\mathrm{p}<0.05)$. At the fifth step, perceived social support entered the equation. This model was significant $(\mathrm{F}=13.906, \mathrm{df}=11$ and $\mathrm{p}<0.001)$ and explained another $7.3 \%$ of variance of QOL. Its regression coefficient was positive and significant $(p<0.01)$. Higher perception of provided social support is associated with higher ratings on QOL. This predictor remained a significant regression coefficient at the last step of the analysis. At the sixth step, religious coping variables entered the equation. This model was significant $(\mathrm{F}=12.441, \mathrm{df}=13$ and $\mathrm{p}<0.001)$, and explained another $1.3 \%$ of variance of the QOL Positive religious coping had positive significant regression coefficient $(p<0.05)$. Negative religious coping style had a negative insignificant regression coefficient $(p>0.05)$. Higher values of positive coping were associated with higher values of QOL also in the last step of the analysis. At the seventh (last) step posttraumatic growth and PTSD symptoms entered the equation. This prediction model was significant $(\mathrm{F}=14.769, \mathrm{df}=15$ and $\mathrm{p}<0.001)$, and explained another $7.3 \%$ of variance of QOL. Posttraumatic growth had a positive and statistically significant regression coefficient $(\mathrm{p}<0.05)$, while PTSD-symptoms 
had a negative and significant regression coefficient $(\mathrm{p}<0.001)$. Higher posttraumatic growth and less intensity of PTSD symptoms were associated with higher values of QOL.

The value of multiple correlation between the linear combination of all predictors included and the criterion variable-QOL was $\mathrm{R}=0.626$. The value of corrected multiple determination coefficient (total $\mathrm{cR}^{2}$ ) indicated that all the predictors taken together shared $36.6 \%$ of the variance with the QOL. Significant F-ratio ( $F=14.769$; $\mathrm{p}<0.001)$ indicated that the model including all the predictors made statistically significant and better prediction of the values on the variable of QOL, compared to model that contained no predictors

Although all prediction models proved to be significant, not all predictors showed significance within these models as well as at the last step of the analysis. In the last model that included all the predictor variables, several variables had significant regression coefficients and thus showed significant independent contributions to the prediction of the values on QOL. Threat appraisals, collaborative coping style and PTSD-symptoms were associated with low ratings QOL. Effect of religiousness on social behavior, perceived social support and posttraumatic growth were associated with high ratings on QOL.

\section{DISCUSSION}

The aim of this study was to examine a relative contribution of the dispositional religiousness, perceived social support, religious coping styles and strategies, primary and secondary stress appraisals, PTSD symptoms and Posttraumatic growth to the QOL as a long term outcome of war traumatic experiences. Aside from the variables that had significant effects on the outcome of trauma, both direct (frequency of traumatic events, primary stress appraisal) or mediating (secondary stress appraisal, coping styles, social support, posttraumatic growth and PTSD symptoms), religiousness and religious coping represented central variables whose effects on QOL were explored. According to LazarusFolkman's transactional model of stress (1993), it was expected to find a significant proportion of variance of QOL to be explained by these variables as they represented personal and environmental dispositions which had an important role in relation between trauma and its long-term outcomes. Within the frame of this model, dispositional religiousness and religious coping may have had direct significant effect on QOL but also they may have had a significant effect on QOL in interactions with other variables such as traumatic events, appraisals and perceived social support. Given the results of our research, we proved the importance of these two groups of variables in the predictions of QOL as a component of long-term posttraumatic outcome.

The correlation analysis showed that each of the variables related to religiousness significantly and positively correlated with QOL. Yet, only effect of reli- giousness on social relations significantly, collaborative coping style and positive religious coping, predict the values of QOL over and beyond traumatic events and stress appraisals. According to the results of the research presented in this paper, the more religiousness have the effect on social behavior, more the subjects were extrinsically oriented, more they used positive religious coping better QOL they perceived. These results are in accordance to a previous research which showed positive correlation of religiousness and religious coping with QOL (Abu-Raiya et al. 2015, Currier et al. 2015). On the other hand, negative effects of trauma exposure and trauma related experience have negative predictive values for QOL which is also theoretically based. Thus, the analysis showed that higher level of trauma related stress and larger frequencies of experienced traumatic events were associated with lower levels of subjects' QOL. This finding is consistent with the results of some previous studies where negative contribution of exposure to trauma to the QOL was confirmed (Priebe 2013, Ajduković 2004). The positive predictive contribution of perceived social support to QOL was also confirmed in this research which is consistent with some other findings (Seidl et al. 2015, Helgeson 2003) in which traumatized people with stronger perception of social support were more likely to have better quality of life in aftermath of war (Araya et al. 2007) or other catastrophic events (e.g. Xiong et al. 2010).

Data analysis showed a significant role of religious coping strategies and religious coping styles in prediction of QOL among the subjects. All three coping styles were negatively associated with QOL. This may be because of later inclusion of positive religious coping which showed significant positive association with QOL, and hierarchically overcome effects of coping styles. A possible implication is that these are overlapping constructs where positive correlation of collaborative coping style with QOL is mainly conditioned by the common part of variance this variable share with religious coping. This commonly occurs among some predictors and the case is described in the literature as suppression effect. Furthermore, even when the relative independent contribution of these coping styles in the prediction of QOL was removed, analysis revealed there was significant contribution of specific groups of variables related to religious coping. Thus, religious coping has proven to be important agent in more positive estimation of QOL.

PTSD-symptoms significantly predicted QOL in a manner that people who reported more PTSD symptoms reported lower QOL. Posttraumatic growth significantly predicted QOL in a manner that people who displayed more personal growth reported higher QOL. These findings are consistent with the results of previous studies where PTSD and posttraumatic growth showed significant direct and/or indirect effect on quality of life perceptions (Schnurr et al. 2006, Teodorescu et al. 2012) and the effects are both indirect and direct (Kashdan \& Kane 2011). 
The study has several limitations that need to be mentioned. First is the time perspective of the study as the data on personal and environmental factors as well as posttraumatic outcomes were collected 20 years after the war in B\&H. It can be assumed that the elaboration processes related to trauma throughout time could not be controlled in this study, which might have biased the responses of the subjects to some extent. The data probably would be more valid if they were collected during earlier periods of time after the war events. Second, the conclusions on some important factors of posttraumatic adjustment may vary depending on what other criteria of posttraumatic adjustment were used. The use of other criteria regarding stress related psychological disorders (anxiety disorders, depression, psychosomatic reactions and addiction problems) might produce other results of data analysis and interpretation. Third, in the analysis of the data that are collected retrospectively, we may expect that some participants aggravate or diminish their problems and consequently exaggerate in their answers. Both categories of examinees, the ones severely struck by trauma and ones who are well adjusted, tend to perceive and interpret their past experiences in the light of their present situation. Fourth, the subjects were not randomly selected as it would have been almost impossible to perform in this research. The sample is defined more as convenient and was formed through the use of ,snowballing" method which gave a chance to subjects from all socio-demographic categories to participate. This also led to somewhat better representativeness of the sample, more valid generalizations and broader scientific implications of the results. Fifth, some other important personality traits, such as hardiness, optimism, locus of control, neuroticism, mastery, etc., as well established predictors of long term posttraumatic adjustment have not been taken into account in this research. A better understanding of the personal dispositions (such as religiousness) and experiences the subjects had during and after the war could be achieved with the use of more individual, clinical approach in data collecting such as qualitative data analysis, detailed interviews or focus groups.

The results of this study have several implications for future research. A practical contribution of this study reflects in the fact that a special attention was given to the importance of religiousness and religious coping strategies as specific predictors of QOL. These data may be helpful in creating medical, psychiatric and psychological interventions and counseling work because taking religiousness and spirituality into account might enable more holistic approach in treating posttraumatic adjustment among war survivors (Sherman et al. 2015, Foy et al. 2013, Hill \& Edwards 2013). Accordingly, a modern approach in dealing with posttraumatic adjustment problems could include providing clients with spiritual and religious help. The aim of this professional approach is to strengthen psychological resilience of the clients in order to make destabilized individuals become more functional and adjusted during transitional processes in post-war communities. The comparison of the results of this study with the results of some previous studies on religious coping (e.g. Abu Raiya \& Pargament 2015) reveal similarities in prevalence and correlates of different religious coping styles within different Christian and Muslim religious groups. The value of these empirical data comes to prominence in organizing psychological intervention where religious and cultural backgrounds of the patients should be taken into account. On the other hand, these interventions should enable various mental health professionals to gather more detailed information on how patients from different religious groups use their religiousness to cope with life stressors and problems thus achieving higher level of their satisfaction with life.

\section{CONCLUSIONS}

The results of this study show that aside from other causal and mediating factors (e.g. frequency of traumatic events, primary and secondary stress appraisals, social support, PTSD symptoms and posttraumatic growth), religiousness and religious coping had significant independent contribution to the prediction of the QOL perceptions. Higher levels of the variables external religiousness, effect of religiousness on social behavior, positive religious coping and lower levels of negative religious coping are associated with higher levels of QOL. Practical implications of the study reflects in the opportunity for the professionals to take into account individuals religious backgrounds and their specific religious coping style while planning psychological interventions.

\section{Acknowledgements:}

The authors wish to thank all the subjects who consented to participate in this study.

\section{Conflict of interest: None to declare.}

\section{Contribution of individual authors:}

Senadin Fadilpašić designed the study, collected data, performed the literature search, participated in the statistical analysis and interpretation of the data

Daniel Maleč participated in the statistical analysis and interpretation of the data; prepared the first draft of the manuscript

Alma Džubur-Kulenović participated in the interpretation of the data; drafted the final version of article revising it critically for important intellectual content

\section{References}

1. Abu-Raiya $H \&$ Pargament KI: Religious Coping Among Diverse Religions: Commonalities and Divergences. Psychology of Religion and Spirituality 2015; 7:24-33. 
2. Abu Raiya $H \&$ Agbaria Q: Religiousness and Subjective Well-Being Among Israeli-Palestinian College Students: Direct or Mediated Links? Social Indicators Research 2015; $1-16$.

3. Abu-Raiya H, Pargament KI, Exline JJ \& Agbaria $Q$ : Prevalence, predictors and implications of religious/spiritual struggles among Muslims. Journal for the Scientific Study of Religion. Advance online publication, 2015.

4. Ajduković D: Social context of trauma and healing. Med Confl Surviv 2004; 20:120-35.

5. Ai A \& Park C: Psychosocial mediation of religious coping styles: A study of short-term psychological distress following cardiac surgery. Personality and Social Psychology Bulletin 2007; 33:867-82.

6. Ano, $G G$ \& Vasconcelles EB: Religious coping and psychological adjustment to stress: A meta-analysis. Journal of Clinical Psychology 2005; 61:461-80.

7. Araya M, Chotai J, Komproe IH \& de Jong JTVM: Effect of trauma on quality of life as mediated by mental distress and moderated by coping and social support among postconflict displaced Ethiopians. Quality of Life Research 2007; 16:915-27.

8. Berg G: The relationship between spiritual distress, PTSD and depression in Vietnam combat veterans. J Pastoral Care Counsel 2011; 65:1-11.

9. Björkman $T \&$ \& Svensson B: Quality of life in people with severe mental illness. Reliability and validity of the Manchester Short Assessment of Quality of Life (MANSA). Nord J Psychiatry 2005; 59:302-6.

10. Bravo-Mehmedbasić A, Kucukalić A, Kulenović AD, Suljić E: Impact of chronic Posttraumatic Stress Disorder on the Quality of life of war survivors. Psychiatr Danub 2010; 2:430-5.

11. Chan CS, Rhodes JE \& Perez JE: A prospective study of religiousness and psychological distress among female survivors of Hurricanes Katrina and Rita. American Journal of Community Psychology 2012; 49:168-81.

12. Currier J, Drescher K, Holland J, Lisman $R$ \& Foy D: Spirituality, Forgiveness, and Quality of Life: Testing a Mediational Model with Military Veterans with PTSD. International Journal for the Psychology of Religion 2015; 2:1-26.

13. Diener E, Suh E, Lucas, RE \& Smith HL: Subjective wellbeing: Three decades of progress. Psychological Bulletin 1999; 125:276-302.

14. Eisenman D, Gelberg L, Liu H \& Shapiro M: Mental health and health-related quality of life among adult Latino primary care patients living in the United States with previous exposure to political violence. JAMA 2003 290; 627-34.

15. Exline JJ, Yali AM \& Sanderson WC: Guilt, discord, and alienation: the role of religious strain in depression and suicidality. J. Clin. Psychol 2000; 56:1481-96.

16. Foy $D W$, Drescher $K D$ \& Smith $M W$ : Addressing religion and spirituality in military settings and veterans' services. In Pargament KI (Ed): APA handbook of psychology, religion and spirituality, 561-76. Washington, DC: American Psychological Association, 2013.

17. Freitag S, Braehler E, Schmidt S \& Glaesmer H: The impact of forced displacement in World War II on mental health disorders and health-related quality of life in late life - a German population-based study. Int Psychogeriatry 2012; 24:1-10.
18. Gerber M, Boals A \& Schuettler, D: The unique contributions of positive and negative religious coping to posttraumatic growth and PTSD. Psychology of Religion and Spirituality 2011; 3:298-307.

19. Harrison MO, Koenig HG, Hays JC, Eme-Akwari, AG, Pargament, KI: The epidemiology of religious coping: a review of recent literature. International Review of Psychiatry 2001; 13:86-93.

20. Hathaway WL \& Pargament KI: Intrinsic religiousness, religious coping, and psychological competence: A covariance structure analysis. Journal for the Scientific Study of religion 1990; 27:339-410.

21. Helgeson VS: Social support and quality of life. Quality of Life Research 2003; 12:25-31.

22. Hill PC \& Edwards E: Measurement in the psychology of religiousness and spirituality: Existing measures and new frontiers. In: Pargament KI (Ed): APA handbook of psychology, religion, and spirituality, 51-57. Washington DC: American Psychological Association, 2013.

23. Kashdan T\& Kane J: Post-traumatic distress and the presence of post-traumatic growth and meaning in life: Experiential avoidance as a moderator. Personality and Individual Differences 2011; 50:84-89.

24. Keane TM, Caddell JM \& Taylor KL: Mississippi Scale for Combat-Related Posttraumatic Stress Disorder: Three studies in reliability and validity. Journal of Consulting and Clinical Psychology 1988; 56:85-90.

25. Koenig HG: Concerns about measuring "spirituality" in research. Journal of Nervous and Mental Disease 2008; 196:349-55.

26. Koenig HG, King D \& Carson VB: Handbook of religion and health (2nd ed.). New York: Oxford University Press, 2012.

27. Linley PA \& Joseph S: Positive change following trauma and adversity: A review. Journal of Traumatic Stress 2004; 17:11-21.

28. Lazarus RS \& Folkman S: Stress, appraisal and coping. New York: Springer Publishing Company, 1984.

29. Levin J, Chatters LM \& Joseph R: Theory in religion, aging, and health: An overview. Journal of Religion and Health 2011; 50:389-406.

30. Ljubotina D: Razvoj novog instrumenta za mjerenje religioznosti. U Zborniku sažetaka XIV. Dani psihologije u Zadru, Sveučilište u Zadru, 2004.

31. Masters KS \& Hooker SA: Religion, spirituality, and health. In Paloutzian RF \& Park CL (Eds): Handbook of the psychology of religion and spirituality (2nd ed), 51939. New York: Guilford, 2013.

32. Paloutzian $R$ \& Park CL: Handbook of psychology of religion and spirituality (2nd ed.). New York, NY: Guilford Press, 2013.

33. Pargament KI: The Psychology of religion and coping: Theory, research, and practice. New York: Guilford Press, 1997.

34. Pargament K, Feuille $M \&$ Burdzy D: The Brief RCOPE: Current Psychometric Status of a Short Measure of Religious Coping. Religions 2011; 2:51-76.

35. Pargament KI, Smith B, Koenig HG \& Perez L: Patterns of positive and negative religious coping with major life stressors. J Sci Study Relig 1998; 37:710-24.

36. Pargament KI, Mahoney A, Exline JJ, Jones $J$ \& Shafranske E: Envisioning an integrative paradigm for the psychology of religion and spirituality. In: Pargament KI (Ed): APA handbook of psychology, religion, and 
spirituality. Washington, 3-19. DC: American Psychological Association, 2013.

37. Pargament KI, Kennell J, Hathaway W, Grevengoed N, Newman $J \&$ Jones $W$ : Religion and the problem-solving process: There styles of coping. Journal for the scientific study of religion 1989; 27:90-104.

38. Park CL \& Slattery J: Religiousness/spirituality and mental health. In Paloutzian RF \& Park CL (Eds): Handbook of the psychology of religion and spirituality (2nd ed.), 540-59. New York: Guilford, 2013.

39. Powell S, Rosner R, Krusman B \& Butollo W: PTSD simptom scale-PSS 3, 1998.

40. Priebe $S$, Huxley P, Knight $S$ \& Evans $S$ : Application and results of the Manchester Short Assessment of Quality of Life (MANSA). International journal of social psychiatry 1999; 45:7-12.

41. Priebe S, Jankovic-Gavrilovic J, Bremmer S, Ajdukovic D \& Franciskovic T: Psychological symptoms as long-term consequences of war experiences. Psychopathology 2013; 46:45-54.

42. Priebe S, Matanov A, Janković J, McCrone P, Ljubotina $D$, Kneževic G, Kucukalic A, Franciskovic T \& Schützwohl $M$ : Consequences of untreated posttraumatic stress disorder following war in former Yugoslavia: morbidity, subjective quality of life, and care costs. CMJ 2009; 50 : 456-76.

43. Rapaport MH, Clary C, Fayyad R \& Endicott J: Qualityof-life impairment in depressive and anxiety disorders. American Journal of Psychiatry 2005; 162:1171-78.

44. Smith BW, Pargament KI, Brant C \& Oliver JM: Noah revisited: Religious coping by church members and the impact of the 1993 Midwest flood. Journal of Community Psychology 2000; 28:169-86.

45. Schnurr P, Lunney C, Bovin M \& Marx B: Posttraumatic stress disorder and quality of life: extension of findings to veterans of the wars in Iraq and Afghanistan. Clin Psychol Rev 2009; 29:727-35.

46. Schnurr PP, Hayes AF, Lunney CA, McFall $M \&$ \&ddo $M$ : Longitudinal Analysis of the Relationship between
Symptoms and Quality of Life in Veterans Treated for Posttraumatic Stress Disorder. Journal of Consulting and Clinical Psychology 2006; 74:707-13.

47. Seidl JNT, Pastorek NJ, DeBakey M, Rema L, Rosenblatt A, Troyanskaya M, Miller B I, DeBakey EM, Romesser J, Lippa S, Sim AH \& Linck J: Factors Related to Satisfaction With Life in Veterans With Mild Traumatic Brain Injury. Rehabilitation Psychology In the public domain 2015; 60:335-43.

48. Sherman M, Harris I \& Erbes C: Clinical Approaches to Addressing Spiritual Struggle in Veterans With PTSD. Professional Psychology 2015; Research and Practice: 46:203-12

49. Sundquist J, Behmen-Vincevic A \& Johansson SE: Poor quality of life and health in young to middle aged Bosnian female war refugees: a population-based study. Public Health 1998; 112:21-26.

50. Tedeschi $R G$ \& Calhoun LG: Trauma and Transformation: Growing in the Aftermath of Suffering. Thousand Oaks: Sage Publications, 1995.

51. Teodorescu DS, Siqveland J, Heir T, Hauff E, WentzelLarsen T\& Lien L: Posttraumatic growth, depressive symptoms, posttraumatic stress symptoms, post-migration stressors and quality of life in multi-traumatized psychiatric outpatients with a refugee background in Norway. Health and Quality of Life Outcome 2012; 10.

52. Vaux A: Social Support: Theory, Research, and Intervention. New York: Praeger, 1998.

53. Witvliet CV, Phipps KA, Feldman ME \& Beckham JC: Posttraumatic mental and physical health correlates of forgiveness and religious coping in military veterans. $J$ Trauma Stress 2004; 17:269-73.

54. Wong-McDonald A \& Gorsuch RL: Surrender to God: An additional coping style? Journal of Psychology and Theology 2000; 28; 149-61.

55. Xiong K, Liu C \& Ningxiu L: Social support and Quality of Life: a cross-sectional study on survivors eight months after the 2008 Wenchuan earthquake BMC Public Health 2010; $10: 573$

Correspondence:

Senadin Fadilpašić, MA

Department of Psychiatry, University Clinical Center Sarajevo

Bolnička 25, 71000 Sarajevo, Bosnia and Herzegovina

E-mail: senadinster@gmail.com 